\title{
CT Diagnosis and Management of Focal Lung Disease
}

\author{
Gerald F. Abbott and loannis Vlahos
}

\section{Learning Objectives}

- To learn the imaging features of benign and malignant pulmonary nodules

- To learn the 2017 revised Fleischner Society guidelines for management of CT detected pulmonary nodules

- To understand the spectrum of subsolid pulmonary nodules, the serial evolution of ground-glass nodules to mixed attenuation nodules, and the significance of their solid components

The diagnosis of focal lung disease has progressed in accuracy in recent decades, paralleling the technological advances of computed tomography (CT). In contrast to chest radiography, the utilization of thin-section CT (HRCT) has enabled radiologists to more accurately determine the imaging characteristics of individual lung lesions and guide patient management in a more precise manner.

Focal pulmonary opacities can be broadly categorized as nodules, masses, or focal parenchymal airspace disease. Nodules are characterized as spherical well-defined opacities measuring up to $3 \mathrm{~cm}$. In practice, this definition also includes more ill-defined or irregular nodules that might be more appropriately considered "nodular opacities." A mass is defined as an opacity (solid or partly solid) measuring $>3 \mathrm{~cm}$ [1]. With its ability to evaluate the density and contour morphometry of nodules and masses, CT allows better char-

G. F. Abbott ( $\square)$

Thoracic Imaging FND-202, Massachusetts General Hospital, Boston, MA, USA

St George's Medical School, University of London, London, UK

I. Vlahos

Department of Radiology, St. George's Hospital and NHS Trust, St George's Medical School, University of London, London, UK e-mail: Johnny.vlahos@stgeorges.nhs.uk acterization of these findings, and the resulting CT densitometry data may be supplemented by more specific CT techniques to determine enhancement (e.g., dual-energy CT), verify the evolution of findings by follow-up CT imaging, assess physiologic activity (PET/CT), and ultimately guide fine-needle aspiration or biopsy.

\subsection{Benign Solid Nodule Features}

CT evaluation may reveal specific benign characteristics of a solitary pulmonary nodule including the identification of calcification or fat within the nodule, aided by the utilization of thin-section contiguous images (1-3 mm) through nodules of interest. Although fat may be evident on visual inspection alone, measurements of fat with such technique should be less than -30 to $-40 \mathrm{HU}$ and often are as low as $-150 \mathrm{HU}$ (Fig. 5.1). Measurements should be performed using a suitable sized region of interest (ROI) that encompasses an area that is still within the nodule on the slices above and below the measured slice. This reduces the risk of an erroneously low measurement due to partial volume average effects of any adjacent low-density lung parenchyma.

There is no absolute Hounsfield unit (HU) measurement that confirms calcification although measurements of $>200$ are usually related to pixels occupied by calcific material. Visual comparison to other thoracic osseous structures is considered sufficient for determining the calcific nature of lesions. The identification of diffuse, central, lamellated, or popcorn-type calcification in a pulmonary nodule is diagnostic of a benign lesion - and all but the latter may be indicative of healed granulomatous disease. Popcorn-type calcification is considered characteristic of a pulmonary hamartoma and when found in combination with intralesional fat is considered diagnostic of that entity. Eccentric calcification is indeterminate-sometimes benign and related to granulomatous disease-but also occurring in malignant lesions such as bronchial carcinoid tumors. Occasionally, eccentric calcification within a lung nodule or mass may reflect a small granu- 

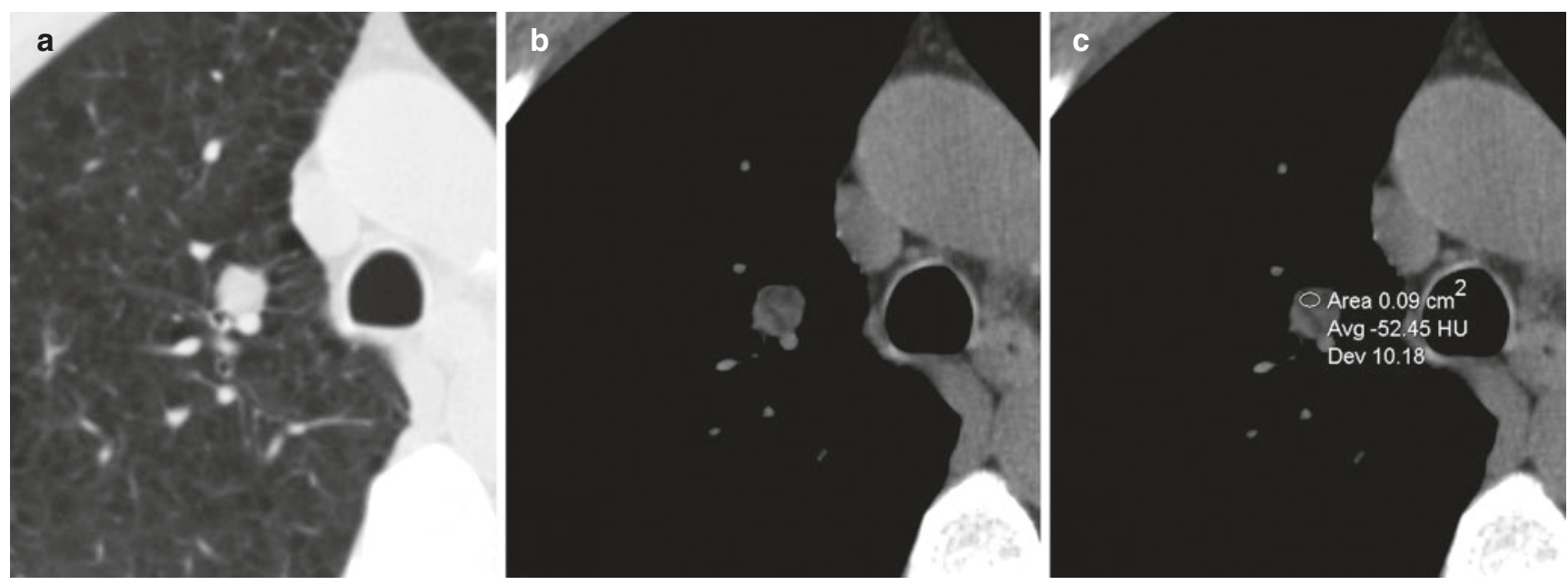

Fig. 5.1 Hamartoma. Composite CT image of a pulmonary nodule in lung window (a) and soft-tissue window (b) shows a well-circumscribed nodule in the right upper lobe that appears heterogeneous on soft-tissue

loma that has been engulfed within an enlarging adjacent neoplasm. Dystrophic or stippled calcifications are also indeterminate-sometimes benign — but well recognized to occur within bronchial carcinoid tumors, non-small cell lung cancer, and small cell carcinoma and are thus not a helpful discriminator between benign and malignant nodules. It is important for radiologists to be familiar with these patterns of calcification that may occur within pulmonary nodules and mass lesions (Fig. 5.2). Furthermore, it is recommended that pulmonary nodules and masses be inspected on coronal and sagittal images in addition to routine axial images. This practice enables not just the verification of maximal lesion dimensions but also clarifies such features as central versus eccentric calcification since the eccentric location of calcification may only be evident in those planes [2].

Other morphological features that are associated with benign lesions include a polygonal, elongated, elliptical, linear, or plaque-like shape, particularly when related to the fissures or pleural surfaces. Indeed such lesions are not all by definition strictly nodules. Some might be best characterized as scars, whereas triangular or elliptoid nodules may represent normal intrapulmonary lymph nodes. These findings are reported with variable incidence by pathologists and similarly with variable incidence and confidence by radiologists.

On CT images, intrapulmonary lymph nodes manifest as perifissural nodules (PFNs) and are routinely demonstrated on thin-section chest CT. Typical PFNs are small $(<10 \mathrm{~mm})$ and more often located in the lower lobes, below the level of the carina. They characteristically have a lentiform, triangular, or polygonal shape with 1-3 interlobular septal extensions and are located on or within $10 \mathrm{~mm}$ of the visceral window (b). Region-of-interest (ROI) evaluation of Hounsfield units (HU) reveals intralesional tissue within the range of fat $(-52 \mathrm{HU})$
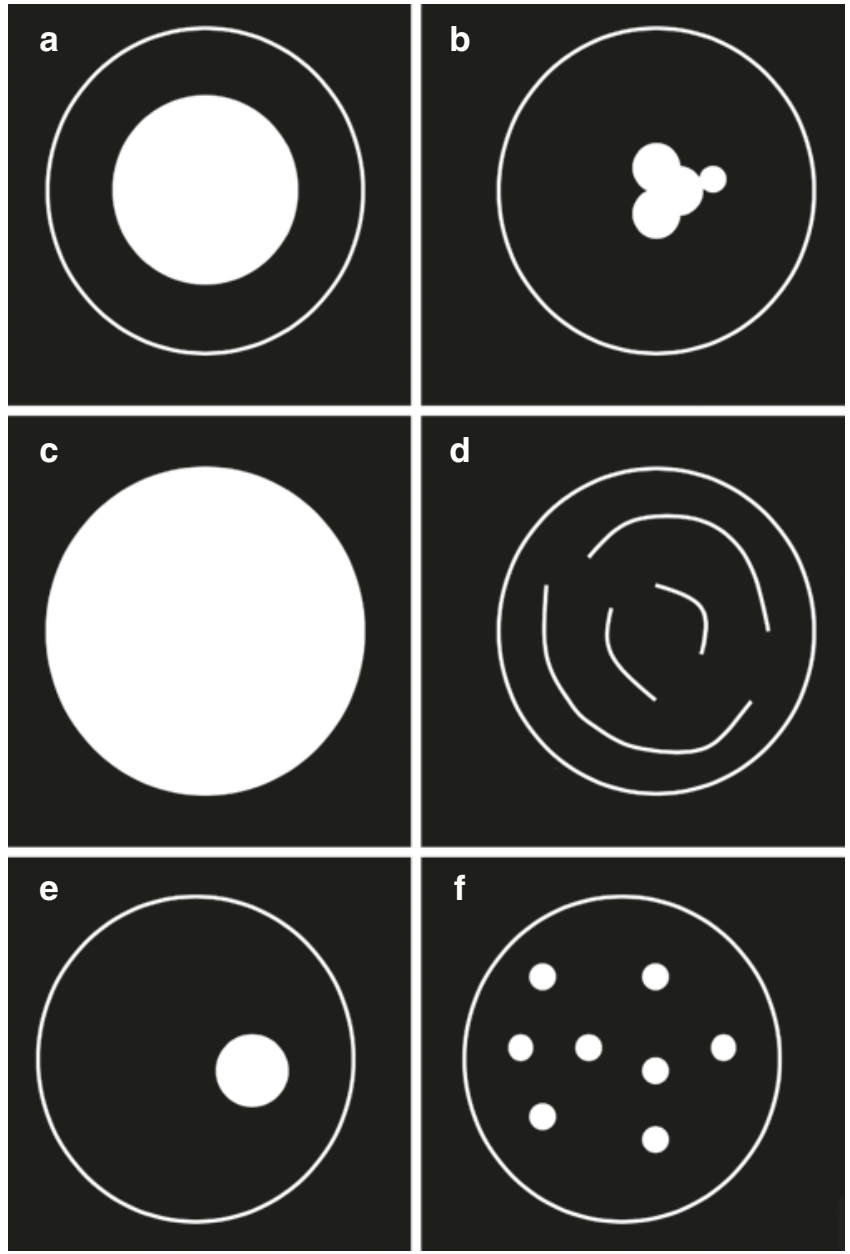

Fig. 5.2 Patterns of calcification. Benign patterns of calcification: (a) (central), (b) (popcorn), (c) (diffuse), and (d) (lamellated/concentric); and indeterminate patterns: (e) (eccentric) and (f) (stippled) 


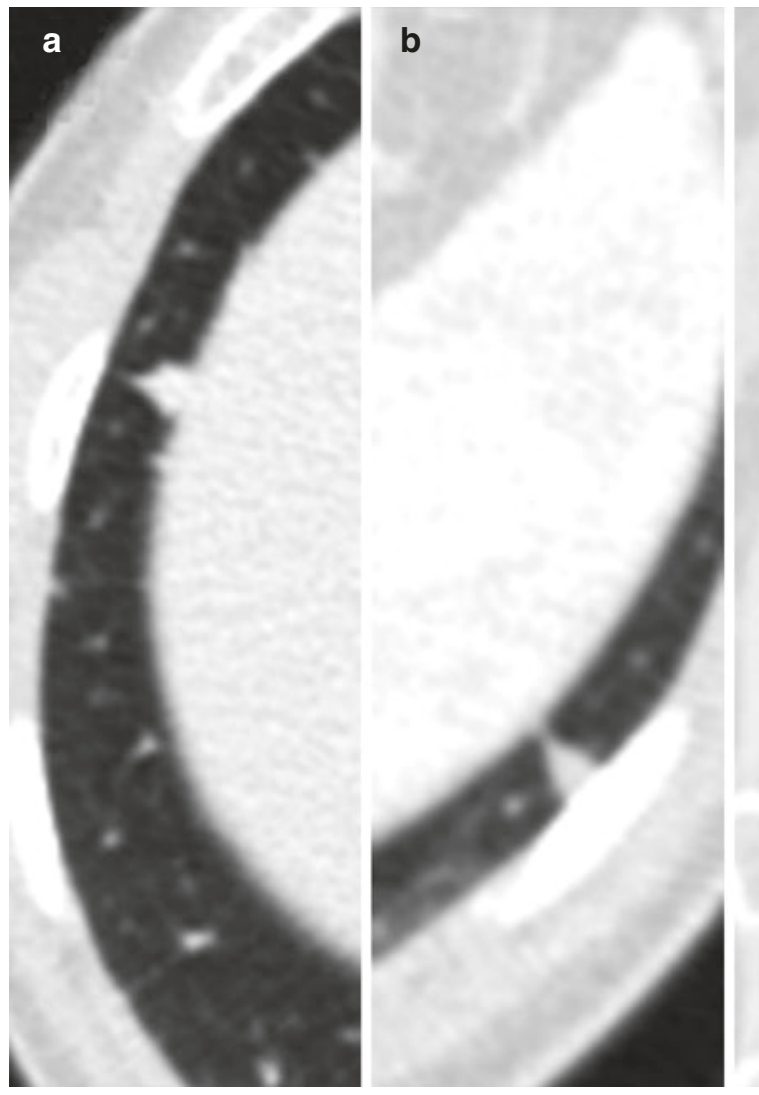

Fig. 5.3 Perifissural nodule (PFN) morphology. Intrapulmonary lymph nodes (a-d) typically manifest as small perifissural nodules $(<10 \mathrm{~mm})$, more often in the lower lobes, with a lentiform, triangular, or polygonal shape with 1-3 interlobular septal extensions, and are located

pleura or a lung fissure (major, minor, or accessory) (Fig. 5.3) [3]. In a recent study, there was moderate inter-reader agreement when classifying nodules as perifissural nodules [4]. Under the revised 2017 Fleischner Society guidelines for management of incidentally detected pulmonary nodules on CT, a PFN with a morphology consistent with an intrapulmonary lymph node does not require follow-up CT, even if the average dimension exceeds $6 \mathrm{~mm}$ [5].

\subsection{Malignant Solid Nodule Features}

Specific features of malignancy are more common in larger pulmonary nodules but relatively uncommon in nodules $<1 \mathrm{~cm}$. Such imaging features as spiculation, microlobulation, pleural tags, satellite nodules, and the presence of a bronchus leading directly into a nodule ("CT bronchus sign") are associated with a higher probability of neoplastic disease although this finding may sometimes occur in inflammatory and infectious diseases, including mycobacterial infection. Cavitation may be an imaging manifestation on or within $10 \mathrm{~mm}$ of the visceral pleura or a lung fissure (major, minor, or accessory). Their characteristic morphology may be more apparent on coronal or sagittal reformatted images

of neoplastic or infectious disease (including bacterial, mycobacterial, and fungal infections) as well as inflammatory disease (e.g., vasculitides, pulmonary Langerhans cell histiocytosis). The detection of thicker-walled cavities on chest radiographs has historically been described as a feature favoring neoplasia, but CT evaluation of the wall thickness of nodules or masses does not corroborate this earlier radiographic interpretation $[6,7]$.

\subsection{Subsolid Nodules}

Subsolid nodules include lesions that are of pure groundglass attenuation on CT as well as those of mixed attenuation-i.e., a combination of ground-glass and solid components. It is well recognized that subsolid lesions with these characteristics are associated with higher prevalence rates of malignancy than solid lesions, particularly when the lesion is of mixed attenuation [8]. Malignant subsolid nodules lie along a spectrum of disease that extends from the small (likely malignant precursor) lesion 


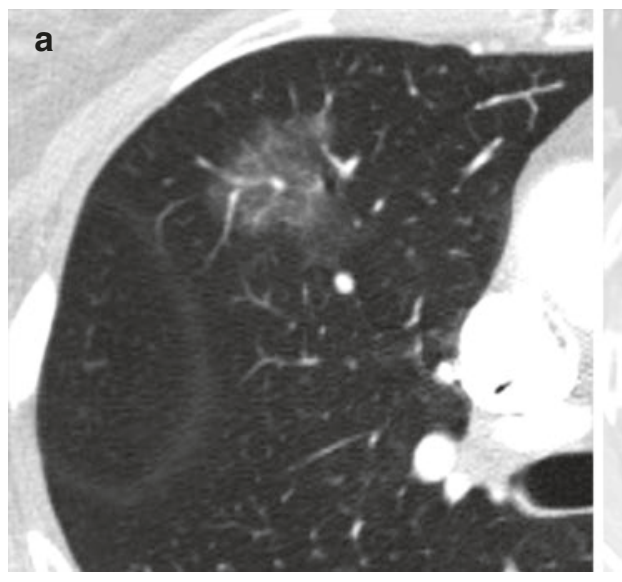

Fig. 5.4 Nodule attenuation patterns. Composite CT image showing a spectrum of attenuation in three pulmonary nodules, ranging from pure ground-glass attenuation (a) to mixed attenuation (b) to solid (c). The

of atypical adenomatous hyperplasia (AAH) through larger ground-glass nodules and mixed attenuation nodules to solid nodules of invasive adenocarcinoma (Fig. 5.4). This spectrum was elucidated by a reclassification of pulmonary adenocarcinoma introduced jointly in 2011 by the International Association for the Study of Lung Cancer, the American Thoracic Society, and the European Respiratory Society [9]. This new classification was based on observations regarding the heterogeneity of subsolid neoplastic lesions, their characteristics of progression, and their clinical impact. These included the demonstration by Aoki and colleagues that AAH and the lower-stage lesions of what was previously termed bronchioloalveolar carcinoma (BAC, Noguchi subtype A, B, C) were associated with lesions that were almost exclusively ground glass in nature. Conversely, the higher-grade lesions (Noguchi D, E, F) were associated with lesions that became progressively more reticular, demonstrated traction bronchiolectasis, and eventually developed increasing solid components $[10,11]$.

The current 2011 histopathologic classification replaces the lesion previously termed bronchioloalveolar carcinoma (BAC). Preinvasive lesions-AAH and adenocarcinoma in situ (AIS) - are typically pure ground-glass lesions less than $5 \mathrm{~mm}$ and $3 \mathrm{~cm}$, respectively, in size. Minimally invasive adenocarcinoma (MIA) is typically a part-solid lesion where the invasive component measures $<5 \mathrm{~mm}$. Larger subsolid lesions with more extensive solid invasive tumor are now termed lepidic predominant adenocarcinoma (LPA). Invasive multifocal mucinous adenocarcinoma replaces the entity previously termed multicentric BAC.

Multiple observers have documented that nodules of pure ground glass or those with minimal solid components typi- solid components in nodules (b) and (c) correspond with areas of tumor invasion

cally progress at a very slow growth rate. In one study a comparison of mean volume doubling times in lung cancer patients with solid, part-solid, or pure ground-glass lesions demonstrated a stepwise increase in CT calculated volume doubling times (853 vs 457 vs 158 days) [12]. Therefore, the demonstration of 2-year stability of a subsolid lesion may not be enough to rule out malignancy. In such cases an initial follow-up CT at 3 months may be performed to demonstrate that the lesion persists and is not inflammatory. Follow-up may then be performed at more prolonged time intervals (1-2 years). When comparing these irregular ill-defined lesions, it can be difficult to measure incremental size, and evaluation should include comparison of comparable contiguous thin-section images and evaluation of whether the ground glass or solid component geographically extends around more vessels or airways. It is also important to note that the natural evolution of these lesions may on occasion include a transient reduction in size, likely related to underlying alveolar collapse.

The definitive determination that a subsolid lesion is malignant can be problematic. A progressive increase in overall size or increase in size of the solid component favors malignancy. PET/CT imaging in these cases is often noncontributory as it is well recognized that these lesions may have low SUV-max activity. Additionally, the evaluation of predominantly ground-glass lesions by CT-guided fine-needle aspiration or biopsy should be treated with caution. The results may be subject to significant sampling error and may vary significantly from those discovered in the excised specimen. The extent of invasive adenocarcinoma in particular can be significantly underestimated by percutaneous needle sampling even if this is directed to the more solid components of a lesion. 


\section{Key Points}

- CT evaluation may reveal specific benign characteristics of a solitary pulmonary nodule including the identification of calcification or fat within the nodule.

- The identification of diffuse, central, lamellated, or popcorn-type calcification in a pulmonary nodule is diagnostic of a benign lesion.

- Subsolid nodules include lesions that are of pure ground-glass attenuation on CT as well as those of mixed attenuation-i.e., a combination of groundglass and solid components.

- Subsolid nodules are associated with higher prevalence rates of malignancy than solid lesions when the lesion is of mixed attenuation.

\subsection{Indeterminate Pulmonary Nodules}

The majority of nodules detected on CT imaging are indeterminate and do not manifest with imaging features that can be definitively categorized as benign or malignant. In a 2005 Mayo Clinic screening series of over 1500 patients, over 3300 indeterminate non-calcified nodules were identified, the vast majority of which were small (4 mm or less) and benign [13]. Even in established smokers, the risk of malignancy in nodules of this size is less than $1 \%$ [14].

In recent years, evidence-based guidelines published by the Fleischner Society have greatly transformed the management of incidental pulmonary nodules detected on CT. The initial Fleischner guidelines, published in 2005, focused on solid pulmonary nodules and were followed by specific guidelines for subsolid nodules in 2013. Those have been supplanted by revised guidelines published in 2017 that encompass both solid and subsolid pulmonary nodules [5]. The recommended changes are based on new data and accumulated experience. For solid nodules, the minimum threshold size prompting routine follow-up CT has been increased to $6 \mathrm{~mm}$, and fewer follow-up examinations are recommended for stable nodules. Time intervals for recommended follow-up are now given as a range rather than a precise time period (Table 5.1). Patient risk factors have also been expanded beyond the previous parameters based on subject characteristics (smoking history, lung cancer in a first-degree relative, exposure to asbestos, radon, or uranium) to include factors related to gender, race, lesion characteristics (size, attenuation, spiculation, upper lobe location), multiplicity, and the presence of emphysema and/ or pulmonary fibrosis (IPF).
Table 5.1 Revised Fleischner guidelines (2017) for solid nodules

\begin{tabular}{|c|c|c|}
\hline $\begin{array}{l}\text { Nodule } \\
\text { type }\end{array}$ & Low risk & High risk \\
\hline $\begin{array}{l}\text { Single } \\
<6 \mathrm{~mm}\end{array}$ & No routine follow-up & Optional CT at 12 months \\
\hline $\begin{array}{l}\text { Single } \\
6-8 \mathrm{~mm}\end{array}$ & $\begin{array}{l}\text { CT at } 6-12 \text { months, then } \\
\text { consider CT at } \\
18-24 \text { months }\end{array}$ & $\begin{array}{l}\text { CT at } 6-12 \text { months, then } \\
\text { CT at } 18-24 \text { months }\end{array}$ \\
\hline $\begin{array}{l}\text { Single } \\
>8 \mathrm{~mm}\end{array}$ & $\begin{array}{l}\text { Consider CT, PET/CT or } \\
\text { tissue sampling at } 3 \text { months }\end{array}$ & $\begin{array}{l}\text { Consider CT, PET/CT, or } \\
\text { tissue sampling at } 3 \text { months }\end{array}$ \\
\hline $\begin{array}{l}\text { Multiple } \\
<6 \mathrm{~mm}\end{array}$ & No routine follow-up & Optional CT at 12 months \\
\hline $\begin{array}{l}\text { Multiple } \\
6-8 \mathrm{~mm}\end{array}$ & $\begin{array}{l}\text { CT at } 3-6 \text { months, then } \\
\text { consider CT at } \\
18-24 \text { months }\end{array}$ & $\begin{array}{l}\text { CT at } 3-6 \text { months, then } \mathrm{CT} \\
\text { at } 18-24 \text { months }\end{array}$ \\
\hline $\begin{array}{l}\text { Multiple } \\
>8 \mathrm{~mm}\end{array}$ & $\begin{array}{l}\text { CT at } 3-6 \text { months, then } \\
\text { consider CT at } \\
18-24 \text { months }\end{array}$ & $\begin{array}{l}\mathrm{CT} \text { at } 3-6 \text { months, then } \mathrm{CT} \\
\text { at } 18-24 \text { months }\end{array}$ \\
\hline
\end{tabular}

MacMahon H, Naidich DP, Goo JM et al. (2017) Guidelines for Management of Incidental Pulmonary Nodules Detected on CT Images: From the Fleischner Society. Radiology 284:228-243.

Table 5.2 Revised Fleischner guidelines (2017) for subsolid nodules

\begin{tabular}{l|l|l|}
$\begin{array}{l}\text { Nodule } \\
\text { type }\end{array}$ & $<6 \mathrm{~mm}$ & $\geq 6 \mathrm{~mm}$ \\
\hline $\begin{array}{l}\text { Single } \\
\text { Ground } \\
\text { glass }\end{array}$ & $\begin{array}{l}\text { No routine } \\
\text { follow-up }\end{array}$ & $\begin{array}{l}\text { CT at } 6-12 \text { months to confirm } \\
\text { persistence, then CT every 2 years } \\
\text { until 5 years }\end{array}$ \\
\hline $\begin{array}{l}\text { Single } \\
\text { Part solid }\end{array}$ & $\begin{array}{l}\text { No routine } \\
\text { follow-up }\end{array}$ & $\begin{array}{l}\text { CT at 3-6 months to confirm } \\
\text { persistence. If unchanged and solid } \\
\text { component remains }<6 \text { mm, annual } \\
\text { CT should be performed for 5 years }\end{array}$ \\
\hline Multiple & $\begin{array}{l}\text { CT at 3-6 months. } \\
\text { If stable, consider } \\
\text { CT at 2 and 4 years }\end{array}$ & $\begin{array}{l}\text { CT at 3-6 months. Subsequent } \\
\text { management based on the most } \\
\text { suspicious nodule(s) }\end{array}$ \\
\hline
\end{tabular}

MacMahon H, Naidich DP, Goo JM et al. (2017) Guidelines for Management of Incidental Pulmonary Nodules Detected on CT Images: From the Fleischner Society. Radiology 284:228-243.

For subsolid nodules, a longer time period is now recommended before initial CT follow-up, and the total length of follow-up has been extended to 5 years (Table 5.2). The revised Fleischner guidelines specify the use of contiguous thin-section CT $(\leq 1.5 \mathrm{~mm})$ and also stress the importance of utilizing axial, coronal, and sagittal images to facilitate the distinction between nodules and linear opacities that can be misleading when only axial images are evaluated (Fig. 5.5).

It is important to note that these guidelines apply to the management of incidentally detected solid and subsolid pulmonary nodules but do not apply to patients younger than 35 years, immunocompromised patients, or patients with cancer. The revised Fleischner guidelines are also not intended for use in lung cancer screening programs. For screening purposes, adherence to the existing American College of Radiology Lung CT Screening Reporting and Data System (Lung-RADS) guidelines is recommended. 
In a separate published statement from the Fleischner Society, recommendations were made regarding the measurement of pulmonary nodules detected on CT images [15]. Those recommendations specify that measurements should be performed on axial sections unless the maximal dimensions lie in the coronal or sagittal plane. In those instances, the measurements should be made on the respective plane and that information should be documented in the radiologic report. Detected lung nodules-including the solid portion of part-solid nodules - should be measured on lung window images, and the dimension of small pulmonary nodules $(<10 \mathrm{~mm})$ should be expressed as the average of maximal long-axis and perpendicular maximal short-axis measurements obtained in the same plane (Fig. 5.6a). Both long- and short-axis measurements should be recorded for larger nodules and masses. Part-solid nodules should be measured in a
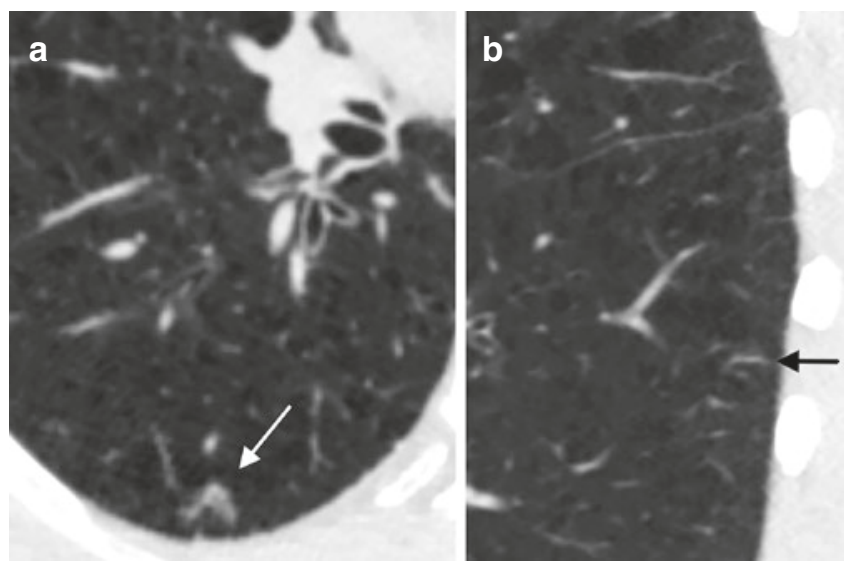

Fig. 5.5 Linear structure misinterpreted as a semisolid nodule. A heterogeneous focal opacity on axial CT ((a), arrow) was reported as a "mixed attenuation nodule," described as "suspicious for lung cancer," and a 3-month follow-up CT was recommended. On sagittal imaging (b), the corresponding finding is a linear opacity (arrow), likely an interlobular septum or small vessel

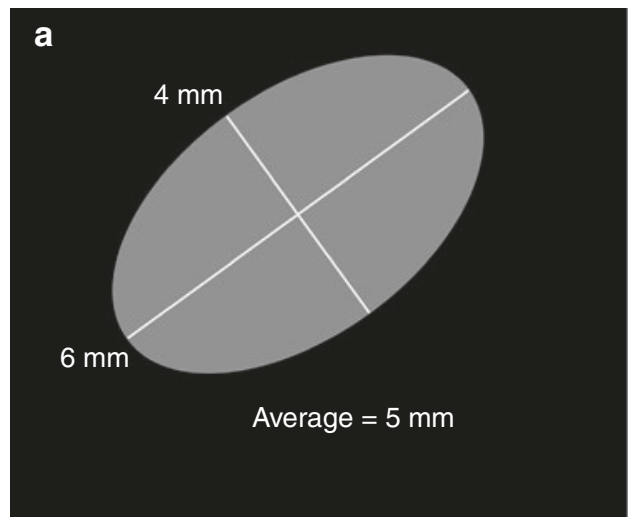

Fig. 5.6 Nodule measurement technique. The size of a solid nodule should be expressed as the average of maximal long-axis and perpendicular maximal short-axis measurements obtained in the same plane (a). Subsolid nodules should be measured in a similar fashion (average similar fashion (average of long and short dimensions) including ground-glass and cystic components, and the maximum diameter of a solid component should also be recorded if $>3 \mathrm{~mm}$ (Fig. 5.6b). It is also recommended that a pulmonary nodule be determined to have changed in size when its average diameter has increased or decreased by at least $2 \mathrm{~mm}$, as smaller changes can be spurious-especially for ill-defined nodules.

\subsection{Role of Computer-Assisted Diagnosis for Solid Nodules}

Computer-aided detection (CAD) is known to improve the detection of pulmonary nodules, although sensitivity is known to be dependent on lesion characteristics including size, density, and location. Technical parameters also affect sensitivity including the thickness of evaluated CT images and vendor-specific issues related to CT algorithm optimization to effect high detection rates with acceptable falsepositive detection rates. Most CAD systems are also accompanied by computer-aided diagnosis (CADx) features for the evaluation of pulmonary nodules.

One of the most useful CADx tools is the ability to perform segmentation of individual nodules, enabling a three-dimensional evaluation of the size and shape of nodular lesions that can be compared with follow-up examinations to determine volumetric growth. This is based upon the observation that the doubling time of benign lesions is far longer than that of malignant lesions [16]. Volumetric evaluation of growth is also more reliable than reader applied uni- or bidimensional measurements of size [17]. Moreover, volumetric evaluation may be more sensitive to the detection of asymmetric growth, a feature that is characteristic of malignant lesions (Fig. 5.7). A commonly utilized threshold for solid lesion volume

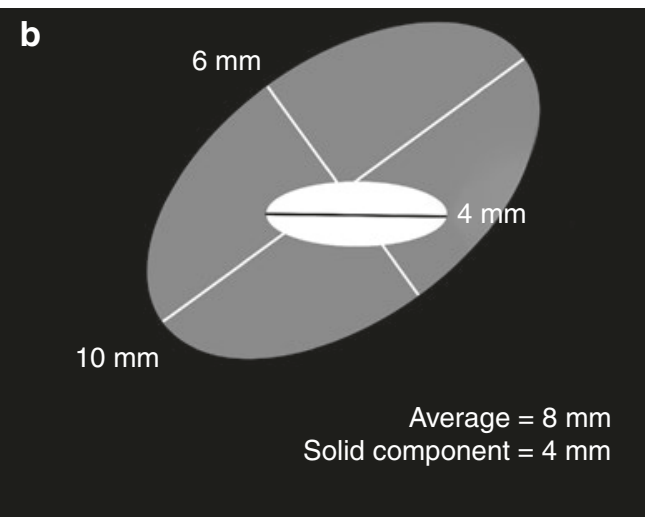

of long and short dimensions) including ground-glass and cystic components, and the maximum diameter of a solid component should also be recorded if $>3 \mathrm{~mm}$ (b) 
Fig. 5.7 Adenocarcinoma of the lung. Composite image of computer-aided 3-D

volumetric evaluation of an irregular pulmonary nodule at baseline (a) and 11 months later (b) demonstrating asymmetric growth
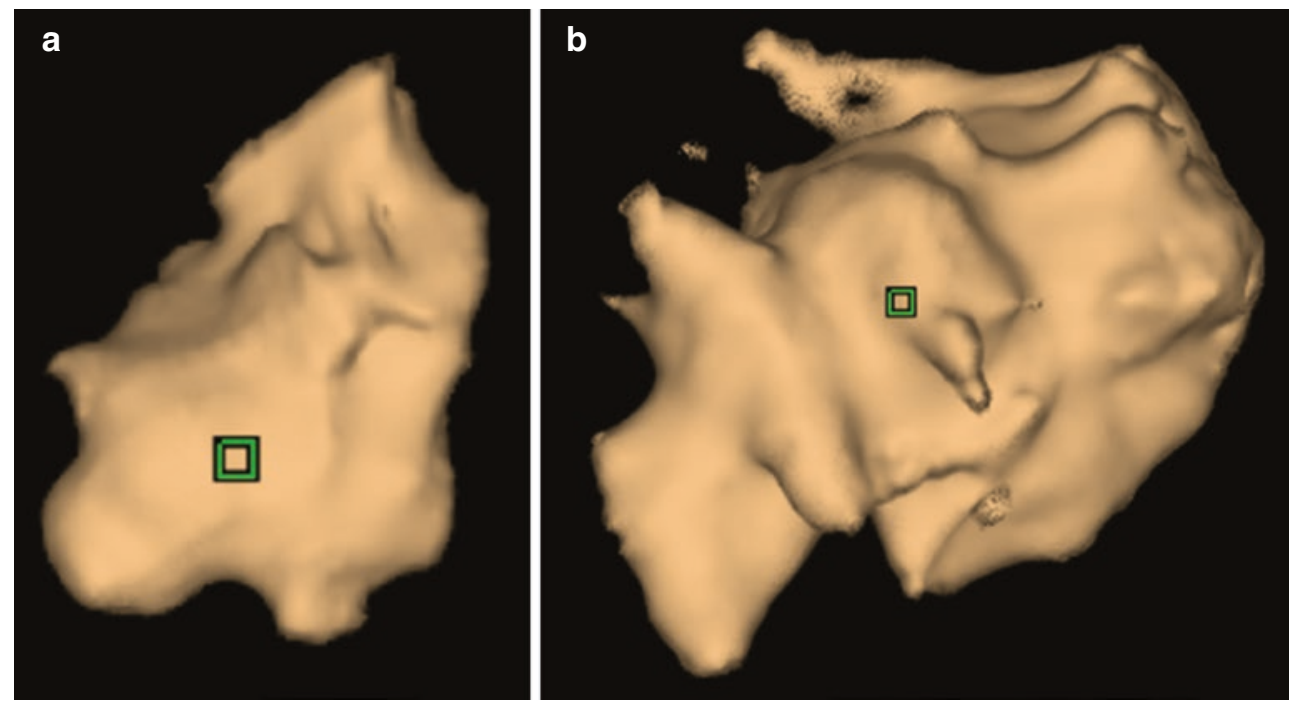

doubling time is 400 days although several authors have advocated a more stringent threshold of 500 days [18-20]. The accuracy and reproducibility of lung nodule segmentation has been confirmed in artificial and porcine models. However, the reproducibility of in vivo human nodule measurements can be demonstrated to vary by up to $15 \%$ when evaluating the same nodule in different phases of inspiration or by utilizing different thickness CT data or software packages [21]. Lesser changes may occur as a result of different reconstruction algorithms or dose variation. The presence or absence of intravenous contrast appears to play a largely inconsequential role. Nonetheless, by ensuring that a similar technique is employed on initial and follow-up examinations, lung nodule volumetry shows great promise and may further reduce the need for follow-up examinations.

\subsection{Focal Parenchymal Airspace Disease}

A variety of disease entities may manifest on CT as focal airspace opacities. The majority of these will be multifocal and infectious or inflammatory in nature, and the diagnosis is often impossible to determine on the basis of imaging findings alone unless there are uncommon specific features present (e.g., ground-glass halo in invasive aspergillosis). However, the differential diagnosis may be narrowed by referring to a combination of imaging features, disease chronicity or progression, response to treatment, and the immune status of the patient.

The presence of cavitation in airspace disease can be helpful although the differential can again be broad incorporating staphylococcal or gram-negative bacterial infections, mycobacterial disease, or fungal infection. Rounded pneumonia is commoner in children but also occurs in adults, usually due to S. pneumoniae. Appearances are mass-like without air bronchograms resulting from propagation of disease through the collateral air-drift mechanisms of the pores of Kohn and the canals of Lambert. Focal consolidative opacity that is chronic may be characterized by associated findings of mild volume loss and traction bronchiectasis, these features being more common in patients with chronic eosinophilic lung disease or organizing pneumonia. The latter may also present with a "reverse halo" appearance (i.e., central ground-glass opacity with peripheral consolidation) although this appearance is not specific to organizing pneumonia and may be a manifestation of other disease processes, including pulmonary infarction. At times, progressive focal airspace disease may be manifestation of neoplastic disease including lepidic adenocarcinoma, lymphoma, or occasionally mucinous metastases from a gastrointestinal primary tumor. Calcification may be present in mycobacterial disease and occasionally amyloidosis.

\subsection{Dual-Energy CT (DECT)}

Recent advances in technology have enabled the clinical implementation of dual-energy CT (DECT) - a technique that utilizes the near-simultaneous acquisition of CT images at two x-ray energy levels-high and low kilovoltages. Modern CT scanners, especially those with tube-current modulation capabilities, have resolved earlier concerns about DECT regarding increased radiation dose. The capabilities of DECT include the creation of virtual unenhanced images (allowing differentiation of calcifications, talc, and enhanced thoracic structures) and the acquisition of pulmonary blood volume (PBV) images that allow differentiation of various parenchymal abnormalities including infarcts, atelectasis, 


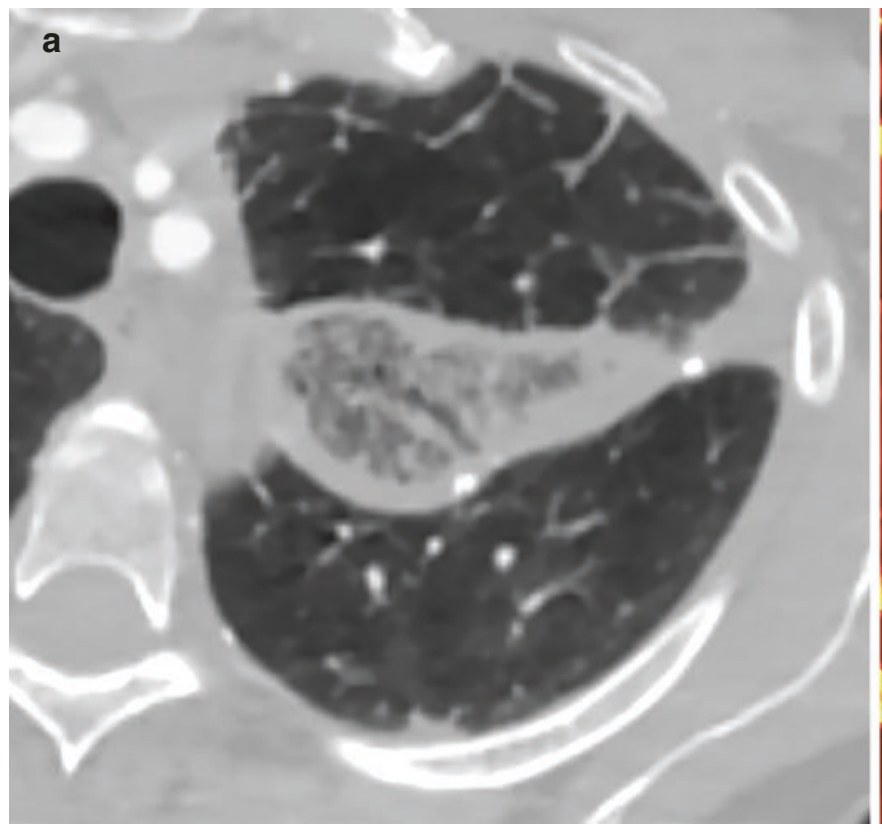

Fig. 5.8 Pulmonary infarction on dual-energy CT. A focal area of consolidation in the left apical region (a) represents lingular infarction (following lingula-sparing left upper lobectomy) and manifests with

and pneumonia (Fig. 5.8). Other applications include enhanced capabilities in pulmonary arterial enhancement and diagnosis of pulmonary embolism with a reduced volume of contrast material [22].

\section{Take-Home Message}

- The identification of diffuse, central, lamellated, or popcorn-type calcification in a pulmonary nodule is diagnostic of a benign lesion.

- Subsolid nodules are associated with higher prevalence rates of malignancy than solid lesions, particularly when the lesion is of mixed attenuation.

- Under the revised 2017 Fleischner Society guidelines for solid pulmonary nodules, the minimum threshold size prompting routine follow-up CT has been increased to $6 \mathrm{~mm}$.

\section{References}

1. Hansell DM, Bankier AA, MacMahon H, et al. Fleischner Society: glossary of terms for thoracic imaging. Radiology. 2008;246:697-722.

2. Ridge CA, Huang J, Cardoza S, et al. Comparison of multiplanar reformatted CT lung tumor measurements to axial tumor measurement alone: impact on maximal tumor dimension and stage. AJR Am J Roentgenol. 2013;2013:959-63.

3. Wang CW, Teng YH, Huang CC. Intrapulmonary lymph nodes: computed tomography findings with histopathologic correlations. Clin Imaging. 2013;37:487-92.

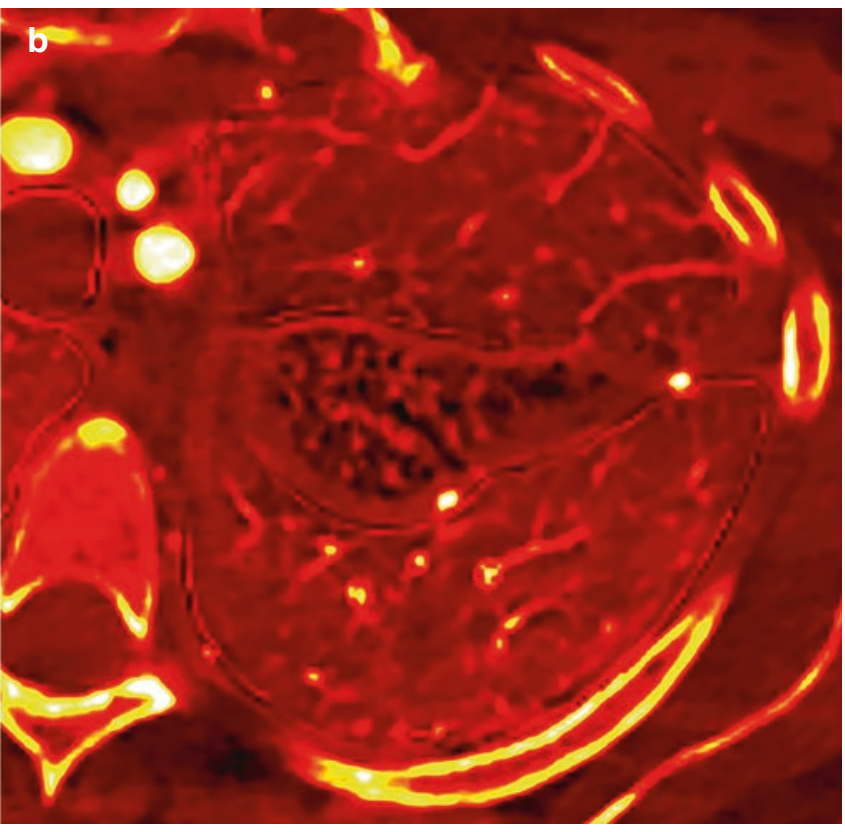

decreased blood flow on a pulmonary blood volume (PBV) image obtained by dual-energy CT (b). The lack of blood flow is in contrast to the normally perfused surrounding lung

4. Schreuder A, vanGinneken B, Scholten ET, et al. Classification of CT pulmonary opacities as perifissural nodules: reader variability. Radiology. 2018;288:867-75.

5. MacMahon H, Naidich DP, Goo JM, et al. Guidelines for management of incidental pulmonary nodules detected on CT images: from the Fleischner Society. Radiology. 2017;284:228-43.

6. Woodring JH, Fried AM, Chuang VP. Solitary cavities of the lung: diagnostic implications of cavity wall thickness. AJR Am J Roentgenol. 1980;135:1269-71.

7. Honda $\mathrm{O}$, Tsubamoto $\mathrm{M}$, Inoue $\mathrm{A}$, et al. Pulmonary cavitary nodules on computed tomography: differentiation of malignancy and benignancy. J Comput Assist Tomogr. 2007;31:943-9.

8. Henschke CI, Yankelevitz DF, Mirtcheva R, et al. CT screening for lung cancer: frequency and significance of part-solid and nonsolid nodules. AJR Am J Roentgenol. 2002;178(5):1053-7.

9. Travis WD, Brambilla E, Noguchi M, et al. International Association for the Study of Lung Cancer/American Thoracic Society/European Respiratory Society international multidisciplinary classification of lung adenocarcinoma. J Thorac Oncol. 2011;6:244-85.

10. Noguchi M, Morikawa A, Kawasaki M, et al. Small adenocarcinoma of the lung. Histologic characteristics and prognosis. Cancer. 1995;75(12):2844-52.

11. Aoki T, Nakata H, Watanabe $\mathrm{H}$, et al. Evolution of peripheral lung adenocarcinomas: CT findings correlated with histology and tumor doubling time. AJR Am J Roentgenol. 2000;174(3):763-8.

12. Hasegawa $\mathrm{M}$, Sone $\mathrm{S}$, Takashima $\mathrm{S}$, et al. Growth rate of small lung cancers detected on mass $\mathrm{CT}$ screening. $\mathrm{Br} \mathrm{J}$ Radiol. 2000;73(876):1252-9.

13. Swensen SJ, Jett JR, Hartman T. E.et al. CT screening for lung cancer: five-year prospective experience. Radiology. 2005;235(1):259-65.

14. Piyavisetpat N, Aquino SL, Hahn PF, et al. Small incidental pulmonary nodules: how useful is short-term interval CT follow-up? J Thorac Imaging. 2005;20(1):5-9.

15. Bankier AA, MacMahon H, Goo JM, et al. Recommendations for measuring pulmonary nodules at CT: a statement from the Fleischner Society. Radiology. 2017;285:584-600. 
16. Yankelevitz DF, Reeves AP, Kostis WJ, et al. Small pulmonary nodules: volumetrically determined growth rates based on CT evaluation. Radiology. 2000;217:251-6.

17. Jennings SG, Winer-Muram HT, Tarver RD, Farber MO. Lung tumor growth: assessment with CT-comparison of diameter and cross-sectional area with volume measurements. Radiology. 2004;231(3):866-71.

18. Jennings SG, Winer-Muram HT, Tann M, Ying J, Dowdeswell I. Distribution of stage I lung cancer growth rates determined with serial volumetric CT measurements. Radiology. 2006;241(2):554-63.
19. Revel MP, Merlin A, Peyrard S, et al. Software volumetric evaluation of doubling times for differentiating benign versus malignant pulmonary nodules. AJR Am J Roentgenol. 2006;187(1):135-42.

20. Honda O, Kawai M, Gyobu T, et al. Reproducibility of temporal volume change in CT of lung cancer: comparison of computer software and manual assessment. Br J Radiol. 2009;82(981):742-7.

21. Bolte H, Riedel C, Muller-Hulsbeck S, et al. Precision of computeraided volumetry of artificial small solid pulmonary nodules in ex vivo porcine lungs. Br J Radiol. 2007;80(954):414-21.

22. Otrakji A, Digumarthy SR, Lo Gullo R, et al. Dual-energy CT: spectrum of thoracic abnormalities. Radiographics. 2016;36:38-52.

Open Access This chapter is licensed under the terms of the Creative Commons Attribution 4.0 International License (http://creativecommons. $\mathrm{org} /$ licenses/by/4.0/), which permits use, sharing, adaptation, distribution and reproduction in any medium or format, as long as you give appropriate credit to the original author(s) and the source, provide a link to the Creative Commons license and indicate if changes were made.

The images or other third party material in this chapter are included in the chapter's Creative Commons license, unless indicated otherwise in a credit line to the material. If material is not included in the chapter's Creative Commons license and your intended use is not permitted by statutory regulation or exceeds the permitted use, you will need to obtain permission directly from the copyright holder. 